\title{
Combinatorial Systems Evolution: Example of Standard for Multimedia Information
}

\author{
Mark Sh. LEVIN ${ }^{1}$, Oleg KRUCHKOV ${ }^{2}$, Ofer HADAR ${ }^{2}$, \\ Evgeny KAMINSKY ${ }^{3}$ \\ ${ }^{1}$ Institute for Information Transmission Problems, Russian Academy of Sciences \\ 19 Bolshoj Karetny Lane, Moscow 127994, Russia \\ ${ }^{2}$ Department of Communication Systems Engineering, Ben-Gurion University \\ Beer Sheva 84105, Israel \\ ${ }^{3}$ Department of Electrical and Computer Engineering, Ben-Gurion University \\ Beer Sheva 84105, Israel \\ e-mail:mslevin@acm.org; kruchkov@cse.bgu.ac.il; hadar@cse.bgu.ac.il; evgenyk@ee.bgu.ac.il
}

Received: May 2007; accepted: February 2009

\begin{abstract}
The article addresses the issues of combinatorial evolution of standards in transmission of multimedia information including the following: (a) brief descriptions of basic combinatorial models as multicriteria ranking, knapsack-like problems, clustering, combinatorial synthesis, multistage design, (b) a description of standard series (MPEG) for video information processing and a structural (combinatorial) description of system changes for the standards, (c) a set of system change operations (including multi-attribute description of the operations and binary relations over the operations), (d) combinatorial models for the system changes, and (e) a multistage combinatorial scheme (heuristic) for the analysis of the system changes. Expert experience is used. Numerical examples illustrate the suggested problems, models, and procedures.
\end{abstract}

Keywords: system evolution, multimedia information, standard, technological trajectories, combinatorial optimization, heuristics, decision making, expert judgment.

\section{Introduction}

In recent years the significance of the evolution or development of engineering systems is increasing (Conradi and Westfetchtel, 1998; Lehman and Ramil, 2001; Levin, 2006, 2007a; Otto and Wood, 1998; Sahal, 1981; Taura and Kubota, 1999). In the main, these studies involve the following directions: (1) basic engineering systems (e.g., transport systems; Sahal, 1981); (2) software systems (Conradi and Westfetchtel, 1998; Lehman and Ramil, 2001); (3) hardware systems (e.g., VLSI; Katz, 1990) and (4) special engineering history bases (Taura and Kubota, 1999). Usually, tree-like models (e.g., $A N D-O R$ tree) are used for modeling the systems and their development/evolution processes (Conradi and Westfetchtel, 1998; Katz, 1990; Levin, 2006). An approach to combinatorial evolution of modular systems, suggested by M.Sh. Levin, is described in the following sources: (i) evolution of DSS COMBI-PC (Levin, 1998); (ii) evolution of devices for 
signal processing (Levin, 2006); (iii) evolution of requirements to topology of communication networks (Levin, 2007a); (iv) analysis of system changes for a building (Levin and Danieli, 2005; Levin, 2006); and (v) general description (Levin, 2006). Generally, it is possible to examine the following three layers (Levin, 2006): (i) products/systems; (ii) requirements to the products/systems; and (iii) standards for the products/systems.

Our discussion article addresses the issues of combinatorial evolution of standards for multimedia information (Bhaskaran and Konstantinidis, 1995; Chiariglione, 1995, 1997; Fomin, 2001; Ghanbari, 1999; Hoang and Vitter, 2002; Jain, 1989; Koenen, 2001; Kuhn, 1999; Le Gall, 1991; Pereira, 2002; Schafer and Sikora, 1995; Sun and Reibman, 2001): (a) a structural description of standard series MPEG (Chiariglione, 1995; Chiariglione, 1997; Fogg et al., 2002; Le Gall, 1991; Mitchell et al., 1996; Watkinson, 2001) and a structural description of system changes for the standards, (b) a set of system changes operations (including multi-attribute description of the operations and some binary relations over the operations), (c) combinatorial models for the changes, and (d) multistage 'technological' trajectories (Levin, 2006, 2007a).

Basic combinatorial models (multicriteria ranking, knapsack-like problems, clustering, combinatorial synthesis, and multistage design) are briefly described. In the article two kinds of models are used: (i) a tree-like system model (AND-OR tree) for the description of standards and (ii) combinatorial models for modeling the changes of standards (e.g., multicriteria ranking, knapsack-like models). A multistage combinatorial scheme (heuristic) and expert judgment are used for the evaluation of the system changes. Numerical examples illustrate the problems, models, and procedures.

\section{Underlaying Combinatorial Problems}

The problem of multicriteria ranking of alternatives is basic one in multiple criteria decision making (Forgionnne, 1991; Simon et al., 1987). The problem is targeted to dividing an initial set of multi-attribute alternatives into linear ordered (by a total quality) subsets. Many well-known techniques can be used for multicriteria ranking problem, for example, (1) multi-attribute utility analysis (e.g., Fishburn, 1970; Keeny and Raiffa, 1976); (2) Pareto approach (Pareto, 1971); (3) interactive methods (e.g., Koksalan et al., 1984); (4) Analytic Hierarchy Process (AHP; Saaty, 1988); (5) outranking techniques (e.g., Roy, 1996; Vincke, 1992); (6) special knowledge bases and neural networks (e.g., Wang and Malakooti, 1992), etc. In our research, multicriteria ranking procedures based on Pareto approach and outranking technique are used.

Knapsack problem is targeted to selection of items while taking into account their utility and some resource constraints. The problem is NP-hard (Garey and Johnson, 1979; Kellerer et al., 2004; Martello and Toth, 1990; Sinha and Zolters, 1979) and may be solved by enumerative methods (e.g., Branch-and-Bound, dynamic programming), approximate schemes with a limited relative error, and heuristics (e.g., Martello and Toth, 1990). Here a simple procedure (based on algorithm by Dantzig) is used. In the case of a multiple choice problem, the units (e.g., items) are divided into groups and items 
from each group are selected while taking into account a total resource constraint. Solving methods for knapsack problem are used for multiple choice problem. Here a simple heuristic (an analogue of algorithm by Dantzig) is used as well.

Clustering problem is a basic scientific problem in many domains (Agrawal and Procopiuc, 2001; Anderberg, 1973; Jain et al., 1999; Johnson, 1967; Levin, 2007b; Mirkin, 2005; Serban and Campan, 2008):

Divide an initial set of elements into clusters (subsets, groups) to minimize the 'distances' (or proximities) between elements in the same clusters (i.e., 'intracluster distances').

The following data can be used as input: (a) parameters of each element and/or (b) proximity ('distance') between elements. The problem is close to the abovementioned multicriteria ranking but without the order over the set of obtained subsets. In network design and management, clustering is used to get local subsystems (e.g., areas). Basic clustering algorithms (agglomerative algorithm, etc.) are described in Agrawal and Procopiuc (2001), Anderberg (1973), Hartigan (1975), Jain et al. (1999), Johnson (1967), Levin (2007b), Mirkin (2005), Serban and Campan (2008). Often polynomial heuristics are used (e.g., agglomerative algorithm). Here an agglomerative algorithm was used (Levin, 2007b; Serban and Campan, 2008).

Combinatorial morphological synthesis is based on Hierarchical Morphological Multicriteria Design (HMMD) and generalizes multiple choice problem (Levin, 1998, 2005, 2006). HMMD extends well-known morphological analysis (Jones, 1981; Zwicky, 1969) by the use of ordinal quality estimates for design alternatives and their compatibility. A brief description of HMMD is as follows (Levin, 1998, 2005, 2006, 2007a; Levin and Danieli, 2005). The examined composite (modular, decomposable) system consists of components and their interconnection (IC) or compatibility. Basic assumptions of HMMD are the following: (a) a tree-like structure of the system; (b) a composite estimate for system quality that integrates components (subsystems, parts) qualities and qualities of IC (compatibility) across subsystems; (c) monotonic criteria for the system and its components; and (d) quality of system components and IC are evaluated on the basis of coordinated ordinal scales. The designations are: (1) design alternatives (DAs) for leaf nodes of the model; (2) priorities of DAs $(r=\overline{1, k} ; 1$ corresponds to the best one); (3) ordinal compatibility (IC) for each pair of DAs ( $w=\overline{0, l} ; l$ corresponds to the best one).

The basic phases of HMMD are: (1) design of the tree-like system model; (2) generation of DAs for leaf nodes of the model; (3) hierarchical selection and composing of DAs into composite DAs for the corresponding higher level of the system hierarchy; and (4) analysis and improvement of composite DAs (decisions).

Let $S$ be a system consisting of $m$ parts (components): $P(1), \ldots, P(i), \ldots, P(m)$. A set of design alternatives is generated for each system part above. The problem is:

Find a composite design alternative $S=S(1) \star \ldots \star S(i) \star \ldots \star S(m)$ of DAs (one representative design alternative $S(i)$ for each system component/part $P(i)(i=\overline{1, m})$ with non-zero IC between design alternatives.

A discrete space of the system excellence on the basis of the following vector is used: $N(S)=(w(S) ; n(S))$, where $w(S)$ is the minimum of pairwise compatibility between 

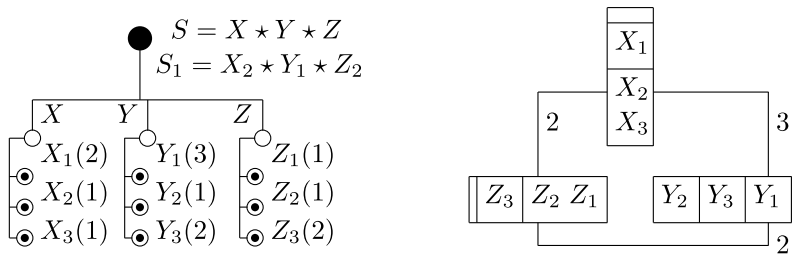

Fig. 1. Example of composition (priorities are shown in parentheses).

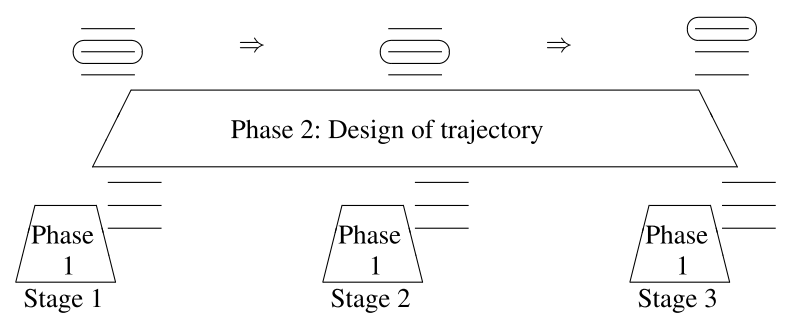

Fig. 2. Multistage design.

DAs which correspond to different system components (i.e., $\forall P_{j_{1}}$ and $P_{j_{2}}, j_{1}=\overline{1, m}$, $\left.j_{2}=\overline{1, m}, j_{1} \neq j_{2}\right)$ in $S, n(S)=\left(n_{1}, \ldots, n_{r}, \ldots, n_{k}\right)$, where $n_{r}$ is the number of DAs of the $r$ th quality in $S$. As a result, we search for composite decisions which are nondominated by $N(S)$. Thus, the following layers of system excellence can be considered: (i) ideal point; (ii) Pareto-effective points; (iii) a neighborhood of Pareto-effective DAs (e.g., a composite decision of this set can be transformed into a Pareto-effective point on the basis of an improvement action(s)). Clearly, the compatibility component of vector $N(S)$ can be considered on the basis of a poset-like scale too (as $n(S))$. In this case, the discrete space of system excellence will be an analogical lattice. Fig. 1 illustrates the composition problem. In the example, composite DA is: $S_{1}=X_{2} \star Y_{1} \star Z_{2}$, $N\left(S_{1}\right)=(2 ; 2,0,1)$.

Multistage design or design of system trajectory is described in Levin $(1998,2006)$. In this case the following solving scheme is used (Fig. 2):

Phase 1. System design for each time stage (HMMD) to get a set of stage decisions.

Phase 2. Design of a system trajectory as a combination of results obtained at the previous phase. Here HMMD is used as well.

\section{Standard}

Fig. 3 depicts a scheme for information processing: $a$ corresponds to video signal, $b$ corresponds to audio signal, $c$ corresponds to synchronization signal, and $d$ corresponds to test signal. This scheme is the basic object for standardization processes. The receiver part has the inverse (for decoding/decompression) structure.

An analysis of the requirements to information processing can be based on the following technological schemes: (1) input data (audio, video, text synchronization data, 


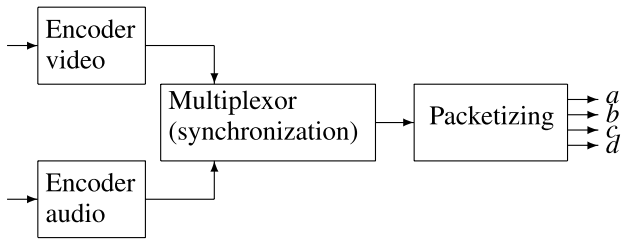

Fig. 3. Scheme of information processing.

synthetic information); (2) processing (coding, network transmission, decoding); and (3) output data (for an user system: a human, an applied system). Thus, requirements can be considered while taking into account the following: (1) object (i.e., data of certain kind, a process); (2) a basic point for the analysis (i.e., a stage of the above-mentioned cycle of information processing: input part, output part, intermediate technological part). In addition, it is reasonable to point out a classification of data as follows: (i) kind (ana$\log$, digital); (ii) time mode (real time, non-real time). Generally, the following two kinds of requirements have to be examined: (1) quality of a result (i.e., resultant information), (2) expenditure (cost, time estimates, etc.).

Quality of the resultant pictures can be based on the following: PSNR, delay, errors, latency, loss (e.g., packets loss, frame loss). From the viewpoint of the standard changes we will consider change operations and the requirements to the operations as follows:

I. Profit of operations: quality of output, level of requirements to input, and level of requirements to technological stages (e.g., coding, network transmission, decoding).

II. Cost of the operations: required additional $\mathrm{R} \& \mathrm{D}$, required additional software development, required additional design of hardware, complexity of an additional manufacturing stage, and simpleness of implementation into existing technologies.

Further, it may be useful to examine a macro-evolution process for standard systems. The line of standards MPEG is examined (Chiariglone, 1997; Fogg et al., 2002; Le Gall, 1991; Mitchell, 1996; Watkinson, 2001). The main chain of the system evolution consists in the following (Fig. 4):

JPEG $\Rightarrow$ MPEG-1 $\Rightarrow$ MPEG-2 $\Rightarrow$ MPEG-4.

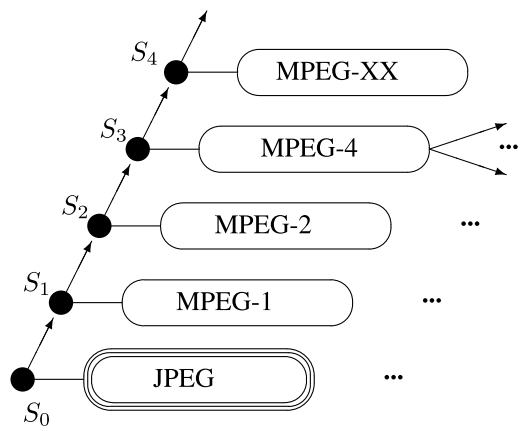

Fig. 4. Macro-evolution process. 


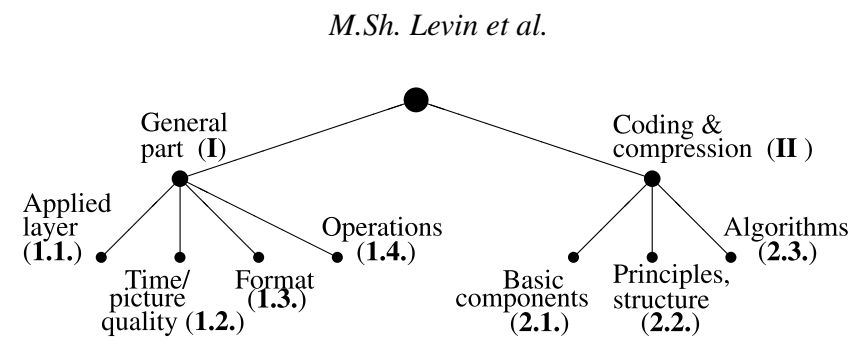

Fig. 5. Generalized structure of standard.

Table 1

Structure of standard

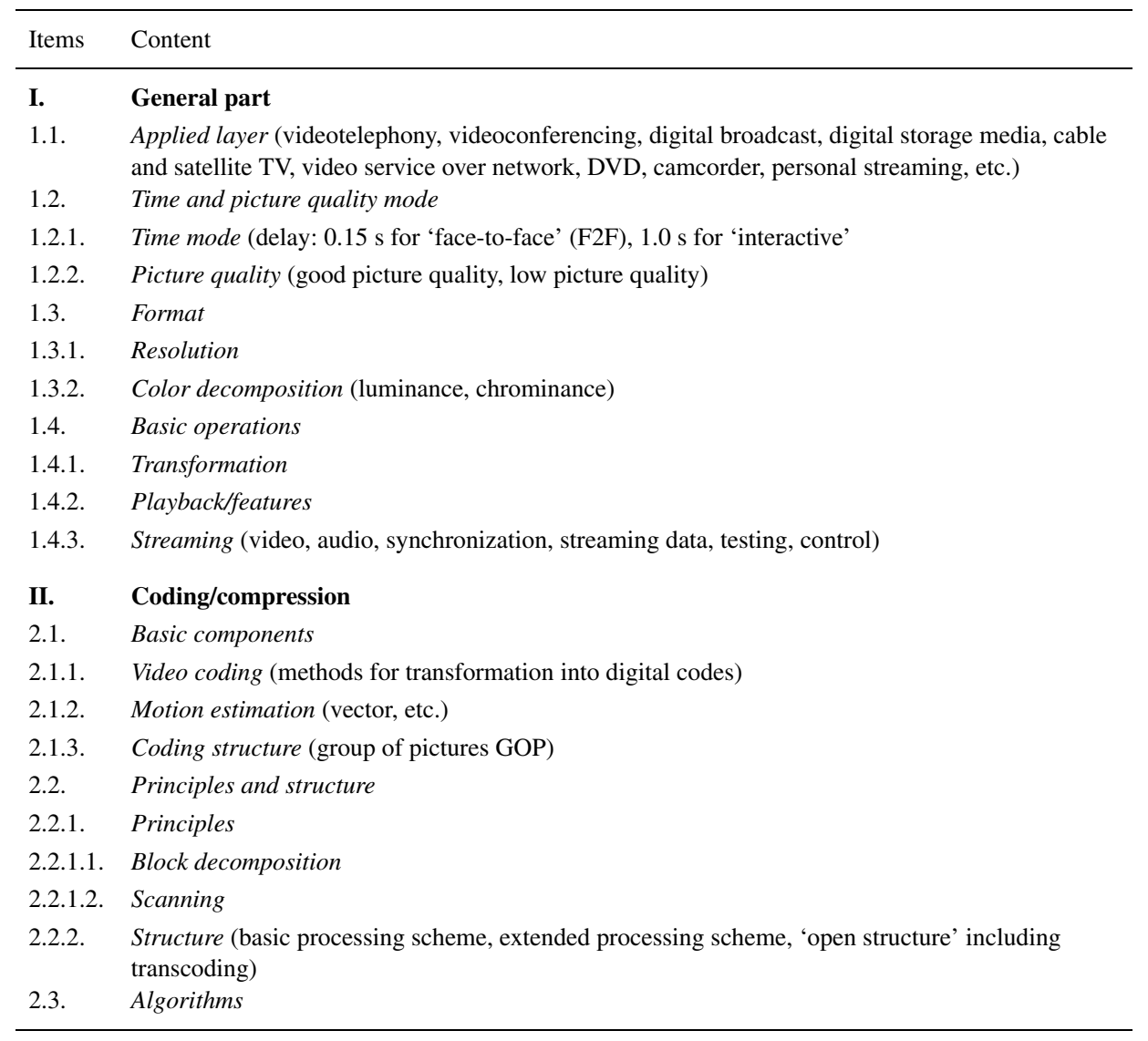

Here a structural description of standards for video information processing is considered as the following set of basic properties, which are organized by a tree (Fig. 5, Table 1). In the main, algorithms are not examined in this article.

The described generalized structure of standards (Fig. 5, Table 1) is used as a basis to examine the MPEG standards. Descriptions of MPEG-1, MPEG-2, and MPEG-4 are presented in Table 2 . 
Table 2

Description of MPEG-1, MPEG-2, MPEG-4

\begin{tabular}{|c|c|c|}
\hline Items & MPEG-1 & MPEG-2 \\
\hline$\overline{1.1}$ & $\begin{array}{l}\text { Bit rate: } 64 \mathrm{kbit} / \mathrm{s}- \\
2 \mathrm{Mbit} / \mathrm{s}, \text { digital media } \\
\text { storage, computer \& tele- } \\
\text { communication networks }\end{array}$ & $\begin{array}{l}\text { Bit rate: } 4-80 \mathrm{Mbit} / \mathrm{s} \text {, digital broadcast } \\
\mathrm{TV} \text {, high quality storage media, cable } \\
\text { satellite TV, video service over the } \\
\text { networks }\end{array}$ \\
\hline 1.2 .1 & Delay & $\begin{array}{l}\text { Real time, low delay } 500-700 \mathrm{~ms} \text {, } \\
\text { delay between audio and video } \\
\approx 300 \mathrm{~ms}\end{array}$ \\
\hline 1.2 .2 & $\begin{array}{l}\text { No error, low picture } \\
\text { quality }\end{array}$ & $\begin{array}{l}\text { Good picture quality by the following } \\
\text { basic modes: error detection, } \\
\text { resynchronization, and data recovery }\end{array}$ \\
\hline 1.3 .1 & $\begin{array}{l}\text { Low resolutions } \\
(\mathrm{CIF}, \mathrm{QCIF})\end{array}$ & $\begin{array}{l}\text { CIF, QCIF, full D1, Half D1, HDTV, } \\
\text { high resolution (NTSC, PAL) }\end{array}$ \\
\hline 1.3 .2 & (Sampling) $4: 2: 0$ & $\begin{array}{l}\text { (Sampling) } 4: 2: 0,4: 2: 2 \text {, } \\
4: 4: 4 \text { (high profile) }\end{array}$ \\
\hline 1.4 .1 & $\begin{array}{l}\text { Audio transformation, } \\
\text { moving picture information, } \\
\text { combination of audio/visual } \\
\text { information (system level) }\end{array}$ & $\begin{array}{l}\text { (1) Coding: audio transformation, } \\
\text { moving picture information, } \\
\text { combination of audio/visual } \\
\text { information; (2) Dolby Digital, DVD } \\
16 \times 9 \text { (TV) and scalability as follows: } \\
\text { SNR (quality), spatial, temporal }\end{array}$ \\
\hline 1.4.2 & $\begin{array}{l}\text { Random access, fast } \\
\text { forward/reverse search, } \\
\text { reverse playback, } \\
\text { audio/visual synchroniza- } \\
\text { tion, good error behavior, } \\
\text { delay, editing, format, rate }\end{array}$ & $\begin{array}{l}\text { Random access, fast forward/reverse } \\
\text { search, reverse playback, audio/ visual } \\
\text { synchronization, good error behavior, } \\
\text { delay, editing, format, rate control, } \\
\text { scalability }\end{array}$ \\
\hline
\end{tabular}

MPEG-4

Bit rate: $24-1024 \mathrm{kbit} / \mathrm{s}$,

digital cable, camcorder,

WEB, security for applica-

tions, interactive mode

Delay 500-700 ms

Variable (used

independent)

From sub-QCIF to 'Studio'

(Sampling) $4: 2: 0$,

$4: 2: 2,4: 4: 4$

delay, editing, format, rate control

1.4.3 Video, audio, synchronization, system stream, and program stream

Video, audio, systems, synchronization, testing, digital storage media control, real time interface, and transport stream

Streaming data (media objects), real-time streams, position of resynchronization marker is anywhere (delay between audio and video is $\approx 300 \mathrm{~ms}$ )

2.1.1 Some transform coding: variable word length coding of coefficient structure

New VLC tables for DCT (non-linear), frame/field compensation

Usage of VLC tables for error detection, coding of natural/synthetic data, high flexibility of coding for audio/video

(a) -2048 to 2047.5 pixel (for half),

2.1.2 -1024 to 1023 pixel (for half), -512 to 511.5 pixel (for full pixel)

2.1.3 As in MPEG-2

2.2.1.1 $16 \times 16$ (macroblock), $8 \times 8$ (block)

2.2.1.2 Progressive scan (zigzag)

2.2.2 Pre-processing, encoding, improvement of postprocessing

-1022 to 1023 pixel (for full pixel),

(b) frame/field motion vector Intra frame: $I$ (intrapicture coded), inter frames: $P$ (coded using motion compensation prediction), $B$ (coded from $I, P$ ), $D$ (for location purpose in fast search) $8 \times 8$

Object-based (VOB)

Progressive scan (zigzag)/interlaced (alternative)

Pre-processing, encoding, improvement of post-processing
Separation of motion and texture data, prioritized transmission of each coded frame 
The following abbreviations are used hereinafter: CIF (Common Intermediate Format), QCIF (Quarter CIF), GDTV (High Definition Television), NTSC or standard of NTSC (National Television Standards Committee), PAl (Phase Alternation by Line, TV standard PAL), Dolbi Digital (format Dolbi Digital), DVD (Digital Versatile Disk), SNR (Signal to Noise Ratio), VLC (Variable-Length Coding), DCT (Discrete Cosine Transform), VBR (Variable Bit Rate, a version of coding in MPEG-2), and CBR (Constant Bit Rate, a version of coding in MPEG-2).

\section{Changes in Standard}

Basic trends of multimedia standard development are as follows:

1. Extension of applications: (a) storage media; (b) broadcast, and (c) WEB applications. Concurrently, it is reasonable to point out the 2 nd development line by time modes: off line mode, on-line (real time) mode, interactive mode.

2. Decreasing a delay.

3. Improvement of quality:

3.1. Decreasing the errors.

3.2. Improvement of resolution.

3.3. Improvement of quality for synchronization.

4. Providing the additional applications: search, archiving, indexing, and multimedia databases.

Further, changes of the MPEG standards are described in Table 3. The revelation of the standard changes is based on comparing the standard parts/components. Figs. 6-10 illustrate the comparison process for some MPEG parts. Here two-stage evolution for some parts/components of MPEG standards is depicted: (a) for part 1.1 (Fig. 6), (b) for component 1.3.1 (Fig. 7), (c) for component 1.4.3 (Fig. 8), (d) for component 2.1.1 (Fig. 9), and (e) for component 2.1.3 (Fig. 10). In Fig. 10, $D$ corresponds to 'fast search', $D$ ' corresponds to possible use in a modified mode ( $D$-frame).

The improvement of communication technology is a significant part of changes in transmission of multimedia information. It is reasonable to point out the following basic contemporary problems of communication technology (Chiariglione, 1997; Sun and Reibman, 2001; Watkinson, 2001): (1) full integration of various networks (wireless, satellite network, broadcast, Internet, etc.); (2) quality of service (QoS) (e.g., delay, delay jitter, packet loss, bit-error rate, burst-error rate, and burst-error length); (3) CBR or VBR; (4) synchronization of video, audio, data, etc.; (5) circuit-switching or packet-switching; and (6) multiplexing.

There exist two kinds of change actions as follows:

I. Global changes: new networks, new communication equipment (new generation of communication satellite, laser-based communication, etc.).

II. Local changes: (a) usage of VBR for CBR networks, (b) effective buffering, (c) smoothing (e.g., statistical multiplexing).

Evidently, local improvements can provide essential increasing of effectiveness for existing communication networks (e.g., quality of service). 
Table 3

Changes

\begin{tabular}{|c|c|c|}
\hline Items & Between MPEG-2 and MPEG-1 & Between MPEG-4 and MPEG-2 \\
\hline 1.1. & $\begin{array}{l}\text { Digital broadcast TV, high quality video/audio } \\
\text { storage, cable satellite TV, video service, high } \\
\text { quality audio transmission, and bit rate (MP3, } \\
\text { stereo, etc.): } 4-80 \mathrm{Mbit} / \mathrm{s}\end{array}$ & $\begin{array}{l}\text { DVD, camcorder, WEB (personal streaming), } \\
24-1024 \mathrm{kbit} / \mathrm{s} \text { (by compression: } 1000 \text { times) }\end{array}$ \\
\hline 1.2.1. & $\begin{array}{l}\text { (i) Low delay (from } 0.15 \text { to less than } 0.15 \text { for } \\
\text { F2F), (ii) real-time delay (1-0.4 s) }\end{array}$ & $\begin{array}{l}\text { (a) Delay (from } 500-700 \mathrm{~ms} \text { ), (b) delay between } \\
\text { audio and video } \approx 300 \mathrm{~ms}\end{array}$ \\
\hline 1.2.2. & $\begin{array}{l}\text { (a) Good picture quality, (b) specific error } \\
\text { resilience modes }\end{array}$ & Use of VLC tables for error detection (possible) \\
\hline 1.3.1. & Full D1, Half D1, HDTV & From QCIF to 'Studio' file format \\
\hline 1.3.2. & (Sampling) $4: 2: 2$ & $4: 4: 4$ \\
\hline 1.4.1. & Scalability (2/3 layers) & Object-based scalability \\
\hline 1.4.2. & Upward/downward & Pause, slow \\
\hline 1.4.3. & $\begin{array}{l}\text { (1) Testing, (2) digital storage media control, } \\
\text { (3) software simulation, (4) real-time interface, } \\
\text { (5) transport stream, and (6) } 10 \text { bit video (Studio } \\
\text { quality) }\end{array}$ & $\begin{array}{l}\text { (a) Streaming data, multiplex and synchronize } \\
\text { the data associated with media objects, transport } \\
\text { over IP, (b) flexibility to position markers } \\
\text { anywhere in a frame }\end{array}$ \\
\hline 2.1.1. & $\begin{array}{l}\text { (a) Non-linear quantization table with increased } \\
\text { accuracy for small values, (b) alternative scan } \\
\text { for DCT coefficient, (c) MV: - 2048-2047.5 } \\
\text { pixel (for half), (d) new VLC tables for DCT } \\
\text { coefficient coding, (e) frame/field scan for DCT } \\
\text { and MV, and (f) no D-frames }\end{array}$ & \\
\hline 2.1.2. & Dual prime motion compensation (for $P$-frame) & $\begin{array}{l}\text { Hybrid coding of natural (i.e., pixel-based) } \\
\text { images with synthetic (computer generated) } \\
\text { scenes }\end{array}$ \\
\hline 2.1.3. & & $\begin{array}{l}\text { Highly flexible way of object representation for } \\
\text { video and audio data }\end{array}$ \\
\hline 2.2. & & Separation of motion and texture \\
\hline \multicolumn{3}{|c|}{ 2.2.1.1. Scale format: $1 \times 1,2 \times 2,4 \times 4$} \\
\hline 2.3 . & & $\begin{array}{l}\text { Scenic material should be acceptable to the } \\
\text { algorithms that may include special modes for } \\
\text { head\&shoulders scenes, graphics, tests, etc. }\end{array}$ \\
\hline
\end{tabular}

Now a basic set of change operations it is possible to describe:

Group 1. Extension of range for data types: storage (interface with applied systems): files, DVD, camcorder $O_{1}$; broadcast (coding/decoding): digital broadcast TV, cable-satellite, video-conferencing $\mathrm{O}_{2}$; and network: video service over network, personal streaming, security for application, interactive mode $\mathrm{O}_{3}$.

Group 2. Change of resolution: design of new equipment for improvement of picture quality: $\mathrm{O}_{4}$ for software, $\mathrm{O}_{5}$ for hardware; change of existing equipment for improvement of picture quality: $\mathrm{O}_{6}$ for software, $\mathrm{O}_{7}$ for hardware; and change of existing communication technology for improvement of picture quality: $O_{8}$ for software, $O_{9}$ for hardware. 


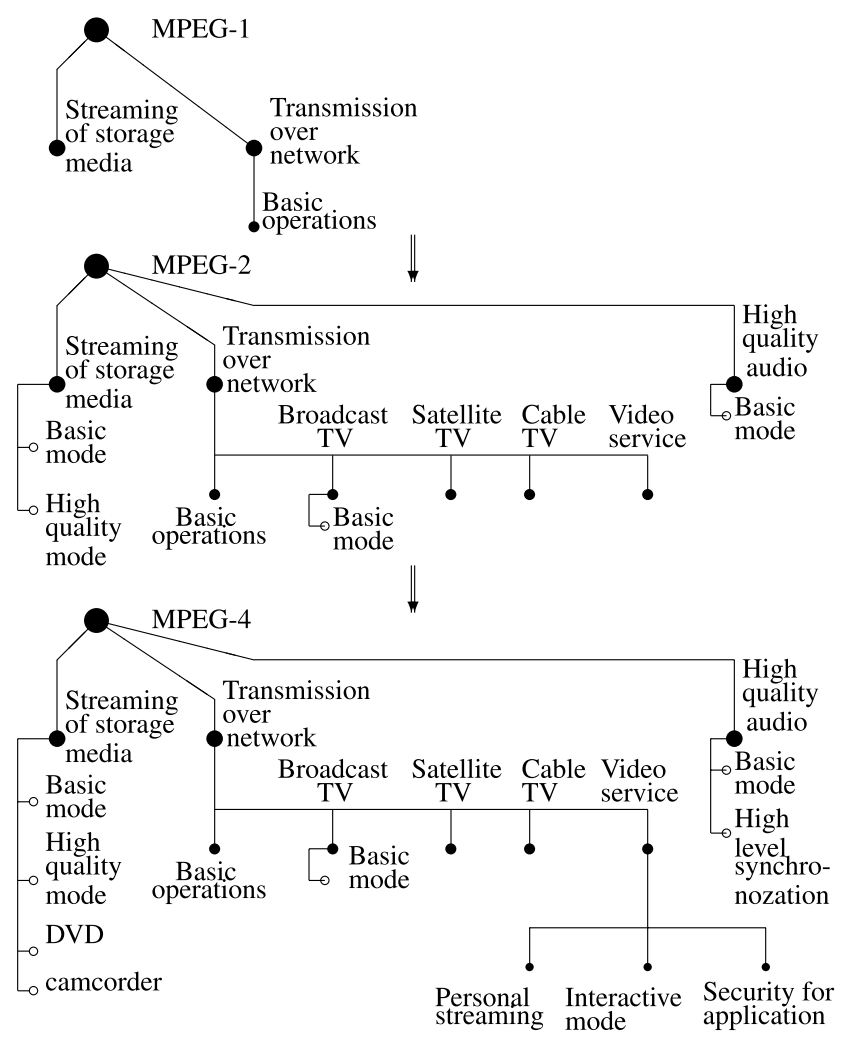

Fig. 6. Applied layer (1.1).

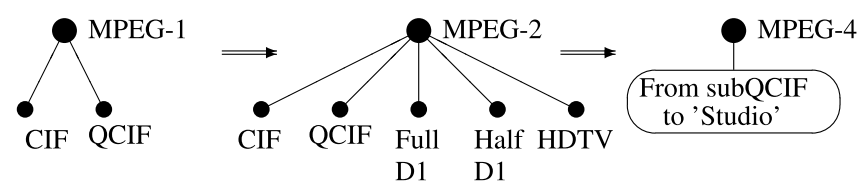

Fig. 7. Resolution (1.3.1).

Group 3. Change of time mode: decreasing a delay $O_{10}$ and realization of real-time mode (conferencing, interactivity) $O_{11}$.

Group 4. Errors: decreasing of losses $O_{12}$ and decreasing a latency $O_{13}$.

Group 5. Transmission: extension of service information (testing, control, etc.) $O_{14}$; additional modes (real time, streaming data) $O_{15}$; support of retrieval modes (e.g., by D-frames) $O_{16}$; and support of retrieval modes increasing the group of pictures (from 2 frames to 7 frames) $O_{17}$.

Group 6. Object and scalability: implementation of object-based approach, i.e., semantic analysis of transmitted information (from frame to object/scene, synchronization markers for objects, global motion detection) $O_{18}$; implementation of scalability $O_{19}$; and variable blocking $O_{20}$. 


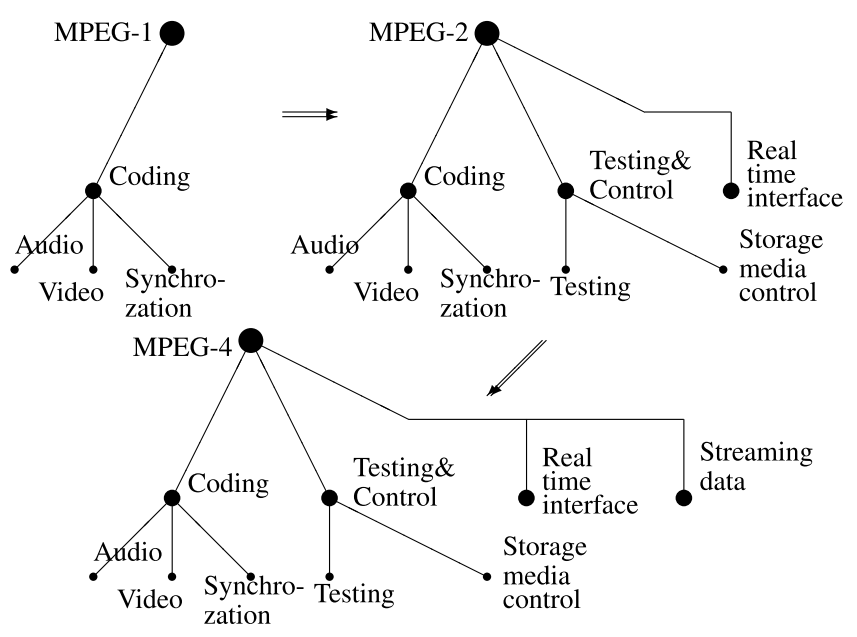

Fig. 8. Transport stream (1.4.3).

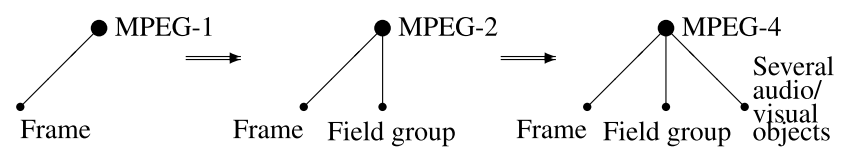

Fig. 9. Video coding (2.1.1).

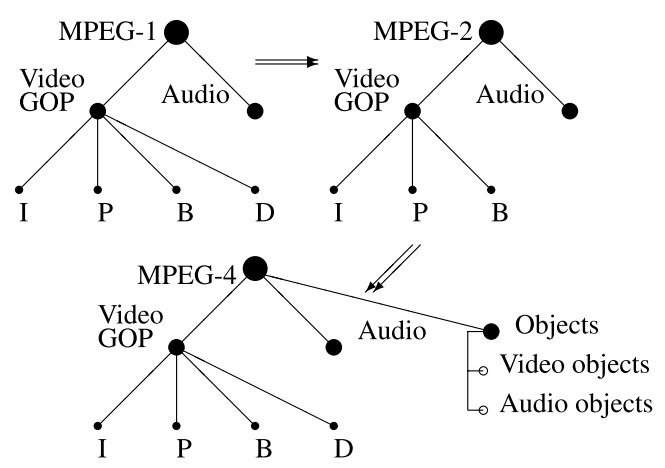

Fig. 10. Coding structure/group of pictures GOP (2.1.3).

Further, it is reasonable to examine the following three kinds of binary relations over the change operations set: (1) equivalence $R^{e}$; (2) complementarity (compatibility) $R^{c}$ (Table 4); (3) condition for the operation $R^{f}: \alpha \rightarrow \beta$, for example: $1 \rightarrow 6,1 \rightarrow 12$, $1 \rightarrow 14$, etc. In Table 4 , the following designations are used: $\star$ corresponds to objectbased relation; $\diamond$ corresponds to soft-hard relation; $\triangle$ corresponds to service-mode relation; and corresponds to time-mode relation. For equivalence $R^{e}$ the following operations pairs are examined: $\left(O_{4}, O_{5}\right),\left(O_{6}, O_{7}\right),\left(O_{8}, O_{9}\right)$, and $\left(O_{18}, O_{20}\right)$. Some structural descriptions of compatibility are shown in Figs. 11 and 12. These relations have to be used 
Table 4

Binary relation compatibility $R^{c}$
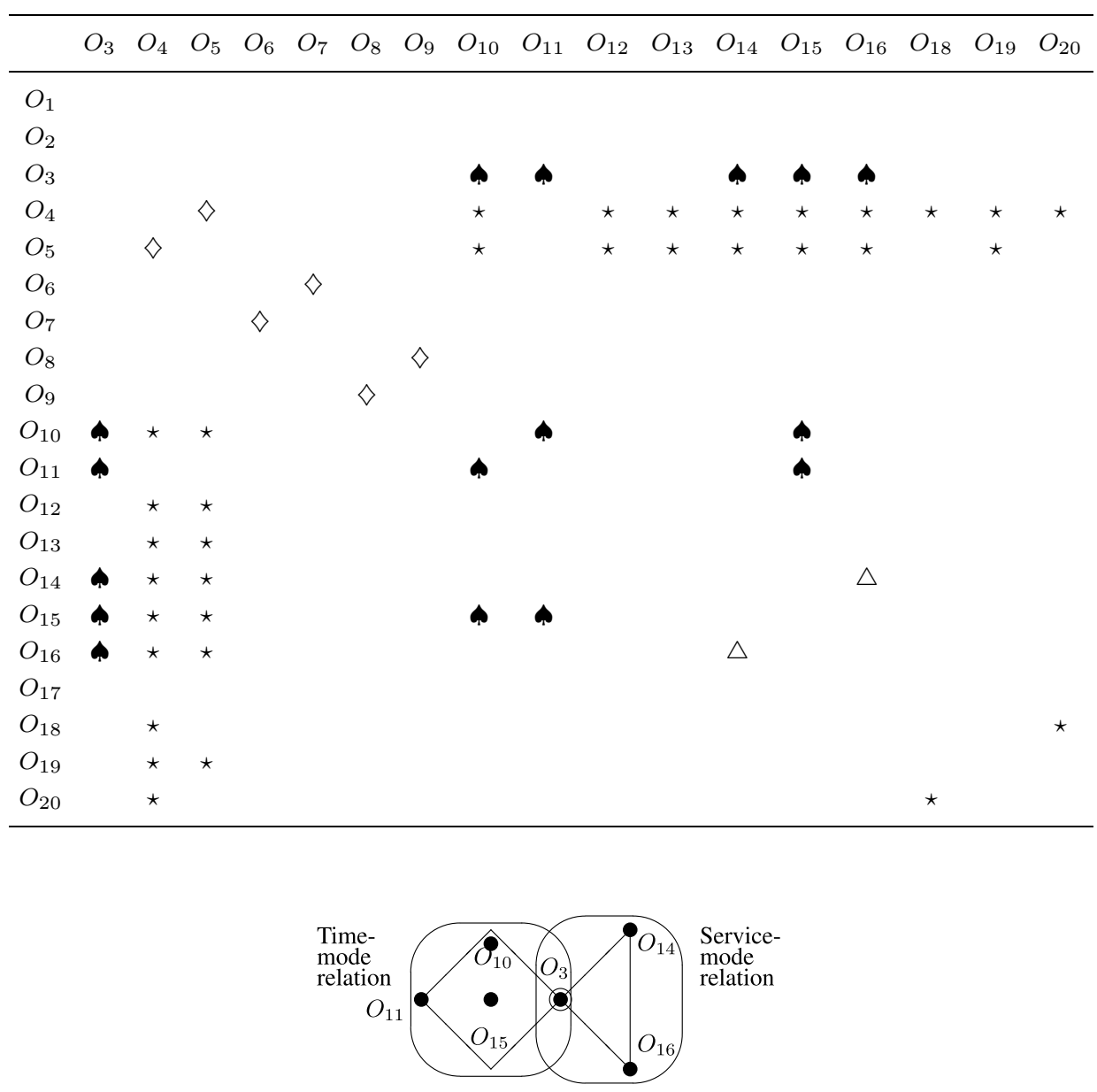

Fig. 11. Compatibility with basic node $\mathrm{O}_{3}$.

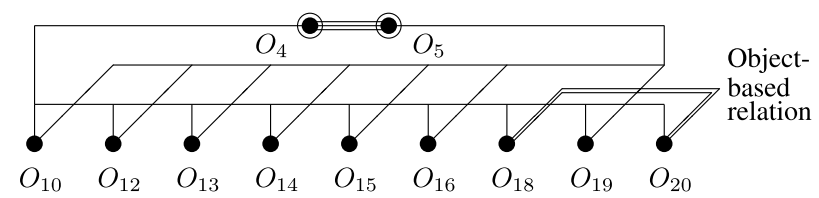

Fig. 12. Compatibility with basic nodes $\mathrm{O}_{4}$ and $\mathrm{O}_{5}$.

as structural constraints. In addition, a time correspondence for each operation is evaluated as a time restriction (Table 5). The following three time stages are used: (a) Stage 1 (past) for some interpolation problems; (b) Stage 2 (near future) for short-term forecast (several years: 2-4); and (c) Stage 3 (future) for long-term forecast (5-10 years). 
Table 5

Correspondence to a time stage

\begin{tabular}{|c|c|c|c|}
\hline & 1: Past & 2: Near future & 3: Future \\
\hline$O_{1}$ & $\star$ & $\star$ & $\star$ \\
\hline $\mathrm{O}_{2}$ & $\star$ & $\star$ & $\star$ \\
\hline$O_{3}$ & $\star$ & $\star$ & $\star$ \\
\hline$O_{4}$ & $\star$ & $\star$ & $\star$ \\
\hline$O_{5}$ & $\star$ & $\star$ & $\star$ \\
\hline$O_{6}$ & $\star$ & $\star$ & $\star$ \\
\hline$O_{7}$ & $\star$ & $\star$ & $\star$ \\
\hline$O_{8}$ & $\star$ & $\star$ & $\star$ \\
\hline$O_{9}$ & $\star$ & - & $\star$ \\
\hline$O_{10}$ & $\star$ & $\star$ & - \\
\hline$O_{11}$ & $\star$ & $\star$ & - \\
\hline$O_{12}$ & $\star$ & $\star$ & $\star$ \\
\hline$O_{13}$ & $\star$ & $\star$ & $\star$ \\
\hline$O_{14}$ & - & $\star$ & $\star$ \\
\hline$O_{15}$ & $\star$ & $\star$ & - \\
\hline$O_{16}$ & - & - & $\star$ \\
\hline$O_{17}$ & - & $\star$ & $\star$ \\
\hline$O_{18}$ & - & $\star$ & $\star$ \\
\hline$O_{19}$ & - & $\star$ & $\star$ \\
\hline$O_{20}$ & - & $\star$ & $\star$ \\
\hline
\end{tabular}

Further, for an analysis of the above-mentioned change operations it is reasonable to consider two main their properties: (1) effectiveness (profit) and (2) required resources. As a result, a multicriteria description and components of the description can be used in optimization problems for the analysis of system changes. Here the following criteria for evaluation of change operations are used:

Group 1. Utility: quality of video $C_{1}$; quality of audio $C_{2}$; quality of synchronization $C_{3}$; quality of data $C_{4}$; and quality of retrieval $C_{5}$.

Group 2. Technological environment: new technological opportunity $C_{6}$.

Group 3. 'Cost': required additional $\mathrm{R} \& \mathrm{D} C_{7}$; required new software $C_{8}$; required new hardware $C_{9}$; and volume of manufacturing $C_{10}$.

Importance weights of the criteria are presented in Table 6. Table 7 contains estimates of the change operations upon criteria and priorities (results of multicriteria ranking for three time stages accordingly; 1 corresponds to the best level).

\section{Illustrative Numerical Examples}

First, multicriteria ranking is considered. Table 7 contains the results of multicriteria ranking of the change operations (priorities) for three cases/stages above: 
Table 6

Weights of criteria

\begin{tabular}{cccc}
\hline & Stage 1 & Stage 2 & Stage 3 \\
\hline$C_{1}$ & 5 & 5 & 5 \\
$C_{2}$ & 3 & 4 & 5 \\
$C_{3}$ & 3 & 4 & 5 \\
$C_{4}$ & 2 & 2 & 4 \\
$C_{5}$ & 0 & 0 & 3 \\
$C_{6}$ & 1 & 3 & 4 \\
$C_{7}$ & -1 & -2 & -4 \\
$C_{8}$ & -3 & -4 & -4 \\
$C_{9}$ & -4 & -4 & -4 \\
$C_{10}$ & -5 & -5 & -5 \\
\hline
\end{tabular}

Table 7

Estimates on criteria and priorities

\begin{tabular}{llllllllllllll}
\hline & $C_{1}$ & $C_{2}$ & $C_{3}$ & $C_{4}$ & $C_{5}$ & $C_{6}$ & $C_{7}$ & $C_{8}$ & $C_{9}$ & $C_{10}$ & & Priorities $p_{i}$ \\
\hline$O_{1}$ & 5 & 5 & 5 & 5 & 5 & 5 & 5 & 3 & 4 & 5 & 2 & 2 & 1 \\
$O_{2}$ & 5 & 5 & 5 & 5 & - & 4 & 5 & 4 & 4 & 5 & 2 & 2 & 2 \\
$O_{3}$ & - & - & - & 5 & 5 & 5 & 5 & 5 & 1 & 2 & 2 & 2 & 2 \\
$O_{4}$ & 4 & 4 & 4 & 4 & 5 & 5 & 5 & 5 & 2 & 3 & 2 & 2 & 2 \\
$O_{5}$ & 4 & 4 & 4 & 4 & 2 & 4 & 5 & 4 & 5 & 4 & 2 & 2 & 2 \\
$O_{6}$ & 3 & 3 & 3 & 2 & 0 & 2 & 3 & 4 & 0 & 1 & 1 & 2 & 2 \\
$O_{7}$ & 3 & 3 & 3 & 0 & 0 & 2 & 3 & 2 & 4 & 3 & 2 & 2 & 2 \\
$O_{8}$ & 5 & 5 & 5 & 5 & 5 & 5 & 5 & 5 & 0 & 4 & 1 & 1 & 1 \\
$O_{9}$ & 5 & 5 & 5 & 5 & 5 & 5 & 5 & 2 & 5 & 5 & 2 & 1 & 1 \\
$O_{10}$ & 3 & 3 & 5 & 3 & 1 & 4 & 5 & 4 & 3 & 2 & 2 & 2 & 2 \\
$O_{11}$ & - & - & - & - & 3 & 5 & 4 & 4 & 5 & 5 & 3 & 3 & 3 \\
$O_{12}, O_{13}$ & 5 & 5 & 5 & 4 & 1 & 2 & 5 & 5 & 1 & 2 & 1 & 2 & 2 \\
$O_{14}$ & 3 & 3 & 5 & 5 & 5 & 5 & 5 & 5 & 3 & 3 & 2 & 2 & 2 \\
$O_{15}$ & - & - & - & 5 & 5 & 5 & 5 & 5 & 1 & 3 & 3 & 3 & 2 \\
$O_{16}$ & - & - & - & - & 5 & 5 & 5 & 4 & - & - & 3 & 3 \\
$O_{17}$ & 5 & - & - & - & 3 & 4 & 3 & 5 & 3 & 4 & 2 & 2 \\
$O_{18}$ & 5 & 2 & 4 & 4 & 5 & 5 & 5 & 5 & 2 & 3 & 2 & 2 & 2 \\
$O_{19}$ & 3 & 3 & 3 & 4 & - & 5 & 4 & 4 & 4 & 4 & 2 & 2 & 2 \\
$O_{20}$ & 5 & - & - & 4 & 3 & 3 & 4 & 5 & 2 & 4 & 2 & 2 & 2 \\
\hline & & & & & & & & & & & & 2 \\
\hline
\end{tabular}

Stage 1. Interpolation problem. Here the following operations are the best ones: $O_{6}$ (change of existing software for improvement of picture quality); $O_{8}$ (change of software for existing telecommunication technology); and $O_{12}$ (decreasing of losses).

Stage 2. Planning for several years. Here the following operations are the best ones: $\mathrm{O}_{8} ; \mathrm{O}_{9}$ (change of hardware for existing telecommunication technology). 


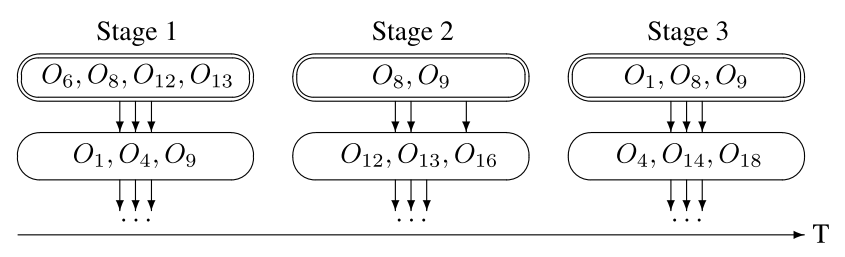

Fig. 13. The best and 'quasi-best' change operations.

Stage 3. Planning for 5-10 year. In this case, the following operations are the best ones: $O_{1}$ (extension of interface with applied systems (storage)); $O_{8}$; and $O_{9}$.

At the same time, it is reasonable to examine some operations which are close to the best ones (i.e., 'quasi-best'):

Stage 1: $O_{1}, O_{4}$, and $O_{9}$.

Stage 2: $O_{1}, O_{6}, O_{12}$, and $O_{13}$.

Stage 3: $O_{4}, O_{14}$, and $O_{18}$.

Fig. 13 depicts the pointed out change operations. Further, it is possible to consider an additional problem:

Design a trajectory of change operations while taking into account their interconnection.

Second, numerical examples of clustering for change operations above are examined. The clustering process can be based on the following approaches: (i) engineering analysis (i.e., expert judgment); (ii) clustering based on the operations estimates (Table 7); (iii) clustering based on binary relation(s) over the operations (e.g., Table 4, Figs. 10, 11); and (iv) a hybrid approach. Here a numerical example for the first case above is considered. The compressed set of operations is: $\left\{O_{1}, O_{4}, O_{5}, O_{6}, O_{7}, O_{8}, O_{9}, O_{10}, O_{12}, O_{14}\right\}$. As a result, the following clusters are obtained (a basic version of the well-known agglomerative algorithm is used): cluster 1: $\left\{O_{1}, O_{9}\right\}$; cluster 2: $\left\{O_{4}, O_{8}, O_{14}\right\}$; cluster 3: $\left\{O_{5}, O_{10}, O_{12}\right\}$; cluster 4: $\left\{O_{6}\right\}$; and cluster 5: $\left\{O_{7}\right\}$.

Third, knapsack problem is used. Here the same compressed set of change operations is examined (as for clustering problem). The estimates upon $C_{10}$ are used as the resource estimates (Table 7). The priorities for Stage 2 (Table 7) are used as estimates of profit (priority 1 is changed by 3 for maximization knapsack problem). On the basis of a simple algorithm (a greedy algorithm, the resource constraint equals 15), the following operations are selected: $\left\{O_{1}, O_{5}, O_{9}, O_{12}\right\}$.

Four, multiple choice problem is considered. Here the results of clustering above are used for our numerical example (a greedy algorithm, the resource constraint equals 15): $\left\{O_{4}, O_{10}, O_{6}, O_{7}\right\}$ (an operation is not selected for cluster 1).

Five, combinatorial morphological synthesis is examined. For the example of combinatorial synthesis the five operation clusters above are considered. Thus the resultant composite decisions (combination of operations) is the following: $S=A \star B \star C \star D \star E$ where $A$ corresponds to cluster 2 and so on. Cluster 4 contains the only one candidate $O_{6}$ and cluster 5 contains the only one candidate $O_{7}$. Thus $D=O_{6}, E=O_{7}$ and a three-component composite system is examined (Fig. 14). 


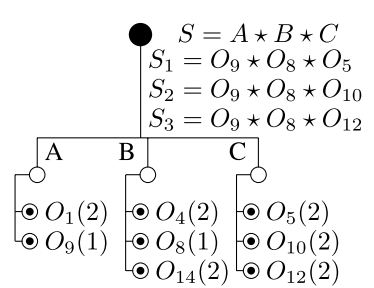

Fig. 14. Example of combinatorial synthesis (priorities are shown in parentheses).

Table 8

Compatibility

\begin{tabular}{ccccccc}
\hline & $O_{4}$ & $O_{8}$ & $O_{14}$ & $O_{5}$ & $O_{10}$ & $O_{12}$ \\
\hline$O_{1}$ & 1 & 1 & 1 & 1 & 1 & 1 \\
$O_{9}$ & 1 & 2 & 1 & 1 & 1 & 1 \\
$O_{4}$ & & & & 2 & 2 & 2 \\
$O_{8}$ & & & & 1 & 1 & 1 \\
$O_{14}$ & & & & 2 & 1 & 1 \\
\hline
\end{tabular}

Estimates of priorities are based on information from Table 7 (Stage 2). Table 8 involves compatibility estimates. It is assumed an initial compatibility estimate equals 1 and for some operation pairs the compatibility estimate is increased (on the basis of compatibility relation $R^{c}$, Table 4 ).

As a result, the following combinations are the best ones: $S_{1}=O_{9} \star O_{8} \star O_{5}, N\left(S_{1}\right)=$ $(1 ; 2,1,0) ; S_{2}=O_{9} \star O_{8} \star O_{10}, N\left(S_{2}\right)=(1 ; 2,1,0) ; S_{3}=O_{9} \star O_{8} \star O_{10}, N\left(S_{3}\right)=$ $(1 ; 2,1,0)$. Note this example has an illustrative character. Evidently, it may be reasonable to take into account other kinds of binary relations as well.

Six, multistage design problem is considered. Here it is reasonable to use a multistage heuristic for the selection and coordination of the change operations while taking into account clusters of change operations, which are obtained on the basis of binary relations above (e.g., Figs. 11 and 12):

Phase 1. Multicriteria ranking of change operations and selection of the best and 'quasi-best' operations (for all time periods; Table 7, Fig. 13).

Phase 2. Extension of the operation sets on the basis of logical constraints (i.e., binary relations).

Phase 3. Generation of alternative change actions for each time stage.

Phase 4. Design of the best trajectories while taking into account interconnection of the change actions at different time stages.

Here for Phase 2 operation clusters from Figs. 11 and 12 are used. The resultant extended sets of the change operations are shown in Fig. 15.

Now it is possible to generate change actions as follows (our example has an illustrative character, in real situation special expert judgment will be required):

Stage 1 (as some two initial points):

$A_{1}^{1}=\left\{O_{6}, O_{8}, O_{12}, O_{13}, O_{4}, O_{5}, O_{3}\right\}$

$A_{2}^{1}=\left\{O_{6}, O_{8}, O_{1}\right\}$. 


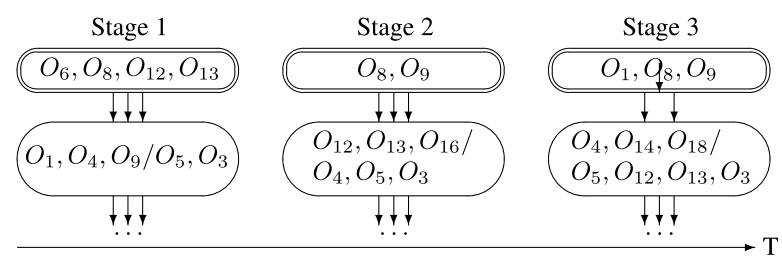

Fig. 15. Extended sets of the best and 'quasi-best' change operations.

Table 9

Compatibility

\begin{tabular}{cccccc}
\hline & $A_{1}^{2}$ & $A_{2}^{2}$ & $A_{1}^{3}$ & $A_{2}^{3}$ & $A_{3}^{3}$ \\
\hline$A_{1}^{1}$ & 3 & 1 & 3 & 2 & 0 \\
$A_{2}^{1}$ & 2 & 3 & 2 & 2 & 1 \\
$A_{1}^{2}$ & & & 3 & 2 & 0 \\
$A_{2}^{2}$ & & & 3 & 3 & 3
\end{tabular}

\section{Stage 2:}

$A_{1}^{2}=\left\{O_{8}, O_{9}, O_{12}, O_{13}, O_{4}, O_{5}, O_{16}, O_{3}\right\}$;

$A_{2}^{2}=\left\{O_{8}, O_{9}\right\}$.

\section{Stage 3:}

$A_{1}^{3}=\left\{O_{1}, O_{8}, O_{9}, O_{12}, O_{13}, O_{4}, O_{5}, O_{14}, O_{18}, O_{3}\right\} ;$

$A_{2}^{3}=\left\{O_{1}, O_{8}, O_{9}\right\} ; A_{3}^{3}=\left\{O_{1}\right\}$.

Fig. 16 illustrates the change actions and some 'technological' (change) trajectories (Da Silveira, 2002; Levin, 1998, 2006). The 'technological' trajectories have to contain the best change operations at each stage and very good compatibility between the selected operations at different stages. This problem corresponds to combinatorial synthesis above. In the numerical example, ordinal estimates of compatibility between change actions are considered. The estimates above are based on expert judgment (Table 9; 3 corresponds to the best level of compatibility). As a result, the following basic trajectories are obtained: $\alpha_{1}=<A_{1}^{1} \Rightarrow A_{1}^{2} \Rightarrow A_{1}^{3}>, \alpha_{2}=<A_{2}^{1} \Rightarrow A_{2}^{2} \Rightarrow A_{3}^{3}>$.

Thus it is possible to examine the obtained 'technological' trajectories. For example, all trajectories contain (at the second stage) change operations which are targeted to improvement of existing communication networks $\left(O_{8}\right.$ and $\left.O_{9}\right)$. Note various optimization problems and approaches can be used for the design of the above-mentioned technological trajectories.

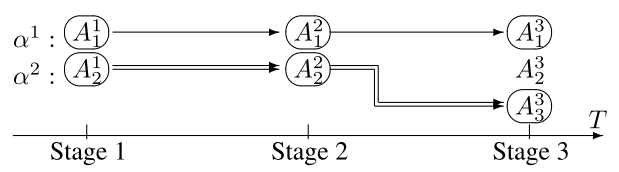

Fig. 16. Illustration for change trajectories. 


\section{Conclusions}

We have described our structural approach to combinatorial evolution of standards in processing of multimedia information. A set of change operations has been proposed and combinatorial optimization models (including forecast) for the changes are examined. Note the analyzed standard changes are significant from the following viewpoints: (i) as 'technological' trajectories of the standards (i.e., standards are considered as some products); (ii) changes of the standards define some requirements to 'technological' trajectories of products in communication systems engineering (e.g., for algorithms, software, hardware). In the future it is reasonable to investigate the following:

1) other engineering systems examples (e.g., communication protocols),

2) usage of more complicated combinatorial models and various algorithms,

3) taking into account uncertainty,

4) usage of traditional artificial intelligence approaches (e.g., expert systems, neural networks), and

5) usage of combinatorial systems evolution in engineering education practice (e.g., student projects).

Acknowledgments. The preliminary research on the examined topic (Dec. 2002-March 2003) was partially supported by Israeli Ministry of Science, Grant No. 2105. At this stage, Mark Sh. Levin was associated for research with Dept. of Communication Systems Engineering at the Ben-Gurion University of the Negev (Israel). A preliminary version of the material was presented at Elsevier server of preprints in computer sciences in 2003. The authors are grateful to the anonymous reviewer for the valuable comments and suggestions, which greatly helped to improve the quality of the article.

\section{References}

Anderberg, M.R. (1973). Cluster Analysis for Applications. Academic Press, New York.

Bhaskaran, V., Konstantinidis, K. (1995) Image and Video Compression Standards: Algorithms and Architectures. Kluwer Academic, Boston.

Chiariglione, L. (1995). The development of an integrated audiovisual coding standard: MPEG. Proc. IEEE, 83(2), 151-157.

Chiariglione, L. (1997). MPEG and multimedia communications. IEEE Trans. Circuits Syst. Video Technol., $7(2), 5-18$.

Conradi, R., Westfechtel, B. (1998). Version models for software configuration management. ACM Comput. Surv., 30(2), 232-282.

Da Silveira, G.J.C. (2002). Improvement trajectories in operations and technology management: concept, process and content issues. Technol. Anal. Strat. Manag., 14(2), 227-240.

Fishburn, P.C. (1970). Utility Theory for Decision Making. Wiley, New York.

Fogg, C.E., Le Gall, D.J., Mitchell, J.L., Pennebaker, W.B. (Eds.) (2002). MPEG Video: Compression Standard. Kluwer Academic, Boston.

Fomin, V.V. (2001). The Process of Standard Making: The Case of Cellular Mobile Telephony. Javaskyla Univ. Printig House, Jyvaskyla.

Forgionne, G.A. (1991). Decision technology system: a vehicle to consolidate decision making support. Inform. Process. Manag., 27(6), 679-697.

Garey, M.R., Johnson, D.S. (1979). Computers and Intractability: The Guide to the Theory of NP-Completeness. Freeman, San Francisco. 
Ghanbari, M. (1999). Video Coding: An Introduction to Standard Codes. IEE Telecommunication Series, Vol. 42. IEE Press.

Hartigan, J.A. (1975). Clustering Algorithms. Wiley, New York.

Hoang, D.T., Vitter, J.S. (2002). Efficient Algorithms for MPEG Video Compression. Wiley, New York.

Jain, A.K. (1989). Fundamentals of Digital Image Processing. Prentice Hall, Englewood Cliffs.

Jain, A.K., Murty, M.N., Flynn, P.J. (1999). Data clustering: a review. ACM Comput. Surv., 31(3), $264-323$.

Johnson, S.C. (1967). Hierarchical clustering schemes. Psychometrika, 2, 241-254.

Jones, J.C. (1981). Design Methods. Wiley, New York.

Katz, R.H. (1990). Toward a unified framework for version modeling in engineering databases. ACM Comput. Surv., 22(4), 375-408.

Keeney, R.L., Raiffa, H. (1976). Decisions with Multiple Objectives: Preferences and Value Tradeoffs. Wiley, New York

Kellerer, H., Pferschy, U., Pisinger, D. (2004). Knapsack Problems. Springer, Berlin.

Koksalan, M.M., Karwan, M.H., Zionts, S. (1984). An improved method for solving multiple criteria problems involving discrete alternatives. IEEE Trans. Syst., Man, Cybern., 14, 24-34.

Koenen, R. (2001). From MPEG-1 to MPEG-21: Creating an interoperable multimedia infrastructure. EE Times. http: //www. eetimes.com/

Kuhn, P. (1999). Algorithms, Complexity Analysis and VLSI Architectures for MPEG-4 Motion Estimation. Kluwer Academic, Boston.

Le Gall, D. (1991). MPEG: A video compression standard for multimedia applications. Commun. ACM, 34(4), 47-58.

Lehman, M.M., Ramil, J.F. (2001). Rules and tools for software evolution planning and management. Ann. Softw. Eng., 11, 15-44.

Levin, M.Sh. (1998). Combinatorial Engineering of Decomposable Systems. Kluwer Academic, Dordrecht.

Levin, M.Sh. (2005). Modular system synthesis: example for composite packaged software. IEEE Trans. Syst. Man. Cybern. Part C, 35(4), 544-553.

Levin, M.Sh. (2006). Composite Systems Decisions. Springer, New York.

Levin, M.Sh. (2007a). Combinatorial technological systems models (examples for communication system). In: 2nd Int. Conf. on Systems Engineering and Modeling, Haifa, pp. 24-32.

Levin, M.Sh. (2007b). Towards hierarchical clustering. In: Diekert, V., Volkov, M., Voronkov, A. (Eds.), CSR2007, LNCS, Vol. 4649. Springer, pp. 205-215.

Levin, M.Sh., Danieli, M.A. (2005). Hierarchical decision making framework for evaluation and improvement of composite systems (example for building). Informatica, 16(2), 213-240.

Martello, S., Toth, P. (1990). Knapsack Problem: Algorithms and Computer Implementation. Wiley, New York.

Mirkin, B.G. (2005). Clustering for Data Mining: A Data Recovery Approach. Chapman \& Hall/CRC, Boca Raton.

Mitchell, J.L., Pennebaker, W.B., Fogg, C.E., Legall, D.J. (Eds.) (1996). MPEG Video Compression Standard. Chapman \& Hall, London.

Otto, K.N., Wood, K.L. (1998). Product evolution: a reverse engineering and redesign methodology. Res. Eng. Des., 10(4), 226-243.

Pereira, F. (2002). The MPEG-4 Book. Wiley, New York.

Pareto, V. (1971). Manual of Political Economy. A.M. Kelley, New York.

Roy, B. (1996). Multicriteria Methodology for Decision Aiding. Kluwer Academic, Dordrecht.

Saaty, T.L. (1988). The Analytic Hierarchy Process. MacGraw-Hill, New York.

Sahal, D. (1981). Patterns of Technological Innovations. Addison-Wesley. Reading.

Schafer, R., Sikora, T. (1995). Digital video coding standards and their role in video communications. In: Proc. IEEE, Vol. 83, pp. 907-923.

Serban, G., Campan, A. (2008). Hierarchical adaptive clustering. Informatica, 18(1), 101-112.

Simon, H.A., Dantzig, G.B., Hogart, R., Plott, C.R., Raiffa, H., Schelling, T.C., Shepsle, K.A., Thaler, R., Tversky, A., Winter, S. (1987). Decision making and problem solving. Interfaces, 17(5), 11-31.

Sinha, P., Zolters, A.A. (1979). The multiple-choice knapsack problem. Oper. Res., 27(3), 503-515.

Sun, M.-T., Reibman, A.R. (2001). Compression Video over Networks. Dekker, New York.

Taura, T., Kubota, A. (1999). A study on engineering history base. Res. Eng. Des., 11, 45-54.

Vincke, Ph. (1992). Multicriteria Decision Aid. Wiley, New York. 
Wang, J., Malakooti, B. (1993). A feedforward neural network for multiple criteria decision making. Comput. Oper. Res., 19(2), 151-167.

Watkinson, J. (2001). MPEG Handbook. Butterworth-Heinemann, UK.

Zwicky, F. (1969). Discovery Invention, Research Through the Morphological Approach. McMillan, New York.

M.Sh. Levin is with the Instute for Information Transmission Problems of the Russian Acad. of Sci. as a senior research scientist. He received the MS degree in radio engineering from Moscow Techn. Univ. for Communication and Informatics (1970), the MS degree in mathematics from Lomonosov Moscow State Univ. (1975), the PhD degree in systems analysis from Russian Acad. of Sci. (1982). Dr. Levin's interests include system design, networking, optimization, decision making. Dr. Levin is a member of IEEE, ACM(SM'06), SIAM, INCOSE. More information can be found at http: / /www.mslevin.iitp.ru/

O. Kruchkov is a research engineer in Dept. of Communication Systems Engineering at the Ben-Gurion University of the Negev, Israel. He received the MS degree in electrical engineering from Belarus State Univ. for Transport (1991). His interests include video information processing.

O. Hadar is a senior lecturer (faculty member) in Dept. of Communication Systems Engineering at the Ben-Gurion University of the Negev, Israel. He received the BS, the MS (cum laude) and the PhD degrees from the Ben-Gurion University of the Negev, Israel, in 1990, 1992, and 1997, respectively, all in electrical and computer engineering. Dr. Hadar's research interests include image compression, video compression, routing in ATM networks, flow control in ATM network, packet video, transmission of video over IP networks, video rate smoothing and multiplexing. Dr. Hadar is a member of IEEE and SPIE.

E. Kaminsky is a PhD student in Dept. of Electrical and Computer Engineering at the Ben-Gurion University of the Negev, Israel. He received the BS and MS degrees in electrical engineering from the university above in 1995 and 1999, respectively. His research interests include video information processing, algorithms for image compression, and VLSI design.

\section{Kombinatoriniu sistemu evoliucija: standarto pavyzdys multimedijos informacijai}

\section{Mark Sh. LEVIN, Oleg KRUCHKOV, Ofer HADAR, Evgeny KAMINSKY}

Straipsnis yra skirtas multimedijos informacijos perdavimo standartu kombinatorinei evoliucijai. Straipsnyje pateikiama: (a) trumpas pagrindinių kombinatorinių modelių, tokių kaip daugiakriterinis rikiavimas, klasterizavimas, kombinatorinè sintezè, daugiapakopis modeliavimas, aprašymas, (b) standartu, skirtų video informacijos apdorojimui (MPEG), aprašymas ir šiu standartu pokyčiu sistemos struktūrinis (kombinatorinis) aprašymas, (c) sistemos pokyčio operaciju aibė (apimanti operaciju požymiu ir binariu sąsaju operacijose aprašyma), (d) pokyčiu sistemos kombinatoriniai modeliai, (e) pokyčiu sistemos analizei skirta daugiapakope kombinatorinè schema. Naudojamos ekspertinès žinios. Daugelis pavyzdžiu iliustruoja pasiūlytas problemas, modelius ir procedūras. 